\title{
'|||||||||||||||||||||||||||||||||||||||||||||||||||||||||||||||||.
}

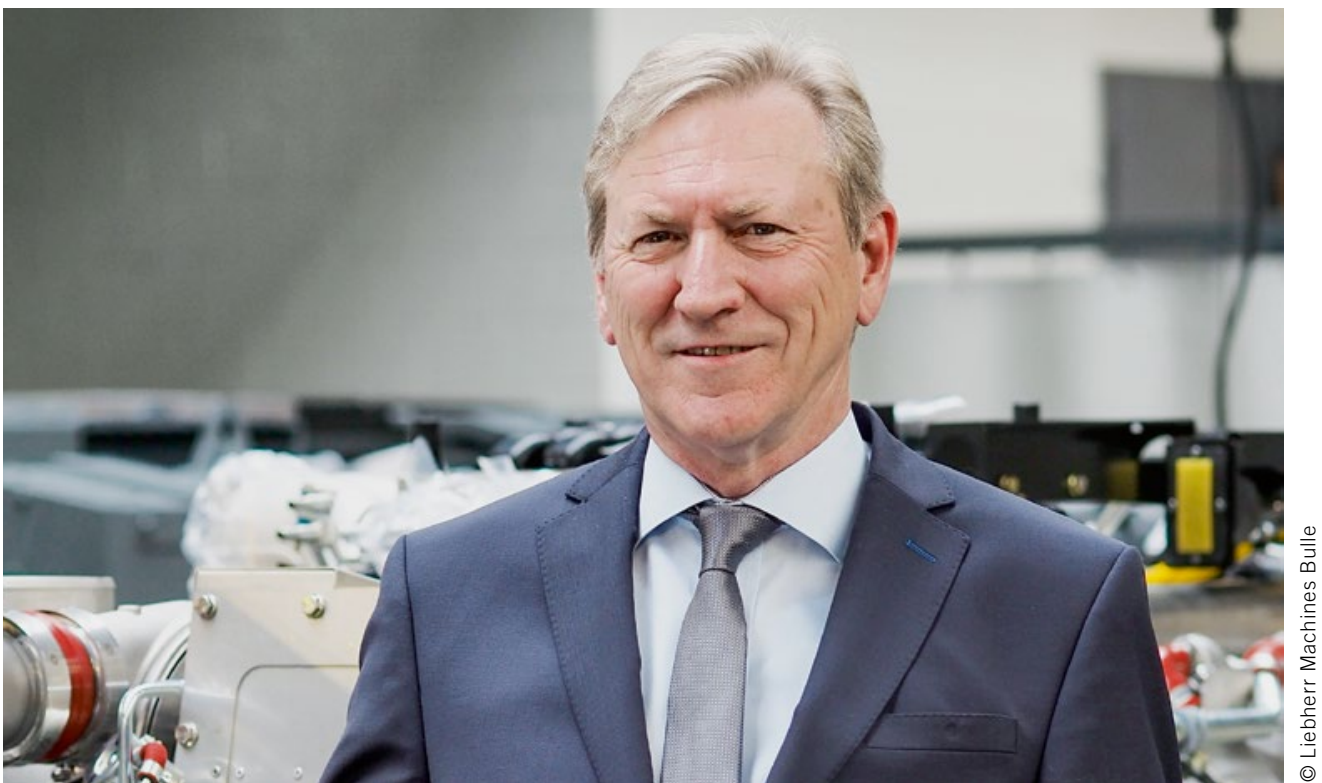

Rudolf Ellensohn

is Managing Director of Liebherr Machines Bulle SA in Bulle (Switzerland)

\section{Electric Drives or Internal Combustion Engines?}

Whether or not, in the future, off-road machines will continue to be powered by internal combustion engines is a hotly-contested topic. Generally, the legislator should not be striving to achieve the desired improvements and set the desired path by specifying a technological solution, since this would all but exclude innovations in the drive sector. Over the past few decades, there have been significant increases in efficiency for the drive systems of machines of practically every type. This will continue to be the case, through further optimisation of components, usage-dependent adaptation and optimisation of the electronic controls. Further improvements of more than $15 \%$ are thoroughly realistic in mobile applications. The target of achieving sustainable development for drive systems may not be solely synonymous with the electrical drive system. According to the current state of knowledge, the energy density of future batteries will not be sufficient to supply heavy-duty machines for eight or more hours of operation.

Policy should specify the objective of developing $\mathrm{CO}_{2}$-neutral energy sources/fuels, and practically pollutant-free drives. $\mathrm{CO}_{2}$ neutrality must be considered for the entire system, that is to say energy generation and drive system. It should further be stipulated that, as from a certain predetermined point in time, fossil fuels should no longer be permitted for use in vehicles and machines. Such an approach would accelerate the development and provisioning of alternative, $\mathrm{CO}_{2}$-neutral fuels and combinations of the various drive systems, and would also help to get the oil companies on board, on this topic. The development and provisioning of alternative fuels, such as PODE, can also - initially as additives for a period of transition - contribute to reducing emissions and increasing efficiency.

The drive systems for off-road machines are going to change. In most machines, hybridisation is already available, offering energy recovery or energy storage. Practically every application already has hydraulic drives installed, the potential of which is not yet optimally utilised in every application.

Sure, there are still some questions to be answered. Yet an approach which only includes a technological orientation is, in my mind, very dangerous and should be reconsidered. Through increasing electrification, energy needs will grow even more quickly than is already the case due to population growth. Are we sure that we will be able to make available four times as much electricity by 2050? Will populations tolerate having considerably more wind and solar farms dotted across the landscape?

Failure to observe the emission thresholds in the private car fleet must not lead to the wholesale calling into question the future viability of internal combustion engines for industry as a whole. The test cycles of utility vehicles and industrial engines are based closely on practice, and correspond to the actual conditions of use, as confirmed through measurements in real-life operation. I do not consider the comprehensive switch from internal combustion engines for utility vehicles and off-road machines to be a realistic prospect in the next 30 years. 